\title{
EFFECT OF THE BENCH SCALE EXTRACTION CONDITIONS ON Pinus radiata BARK EXTRACT YIELD, ANTIOXIDANT PROPERTIES AND COMPOSITION
}

\author{
Valentina Ramos ${ }^{1}$, Carlos Bocalandro ${ }^{2}$, Sebastián Riquelme ${ }^{1}$, Verónica Sanhueza ${ }^{1}$, \\ Estrella Aspé1, Marlene Roeckel ${ }^{1}$, Katherina Fernández ${ }^{1 *}$
}

\begin{abstract}
Many pine bark extracts have antioxidant properties. This work examined bench scale extraction on the yield, the composition and antioxidant properties of Pinus radiata. Acetone solvent $(98.7 \% \mathrm{w} / \mathrm{w}$ at $120^{\circ} \mathrm{C}$ ) yielded maximum phenols concentration, tannins concentration, anti-radical activity (DPPH) and reducing activity (FRAP), although its extraction yield was the lowest. When the organic solvent in the mixture decreased, the chelating activity increased (ICA) and antiradical and reducing activities decreased. The extract largest yield was obtained with water at $120^{\circ} \mathrm{C}$, but the antioxidant properties were relatively poor. Taxifolin (dihydroquercetin) and catechin were the main extract components detected by RP-HPLC. The best extraction conditions for high extractive yield and antioxidant properties was achieved with ethanol/water at $120^{\circ} \mathrm{C}$.
\end{abstract}

Keywords: Antioxidant, bark, bench scale, extraction conditions.

\section{INTRODUCTION}

Lipid oxidation in food can be prevented with the use of synthetic antioxidants such as butylated hydroxyanisole (BHA) and ter-butyl hydroquinone (TBHQ), but the potential carcinogenic properties of these antioxidants limits their use in some countries (Botterweck et al. 2000, Rupasinghe et al. 2010). Thus, natural antioxidants to food lipids are increasingly studied (Kähkönen et al. 1999, Fukumoto and Mazza 2000, Rahim et al. 2008).

The forest and paper industry generates large amounts of organic wastes of different compositions (Jerez et al. 2007a), where pine bark generated in the production process of wood pulp for paper usually is combusted or wasted although several extractable compounds could be used as high value products. Multiple authors have reported the antioxidant bioactivity of pine bark extract (Jerez et al. 2006, Ku et al. 2007, Cortés et al. 2010, Dudonné et al. 2009). In comparison with other pine species, Pinus radiata bark has shown the highest values for polyphenol content and antiradical activity (Jerez et al. 2007a, Ku et al. 2007).

Many studies of natural antioxidant extraction from pine (Jerez et al. 2007a, Jerez et al. 2006, Ku et al. 2007, Jerez et al. 2007b), grape (Kennedy and Jones 2001, Kennedy and Taylor 2003), apple (Rupasinghe et al. 2010) and plants (Heimler et al. 2007, Romani et al. 2006) have been performed, although most have been conducted on a laboratory scale. Indeed, Jerez et al. (2006, 2007b), Ku et al. (2007) and Diouf et al. (2006) used 0.16 L reactors, $0.25 \mathrm{~L}$ extractors and $22 \mathrm{~cm}^{3}$ cells, respectively;

${ }^{1}$ Departamento de Ingeniería Química, Facultad de Ingeniería, Universidad de Concepción. Concepción. Chile. ${ }^{2}$ Unidad de Desarrollo Tecnológico, Av. Cordillera No 2634, Parque Industrial Coronel. Concepción. Chile.

Corresponding author: ^kfernandeze@udec.cl

Received: 12.04.2012. Accepted: 14.07.2012. 
meanwhile other authors (Kennedy and Jones 2001, Kennnedy and Taylor 2003, Rupasinghe et al. 2010, Heimler et al. 2007, Romani et al. 2006) used scales ranging from 30 to $1000 \mathrm{~mL}$ for the extraction of various plants.

Usually, it is difficult to obtain a satisfactory correlation between the extraction variables at laboratory and pilot scales; and larger extraction trials are recommended (Treybal 2001). Therefore, in the present study, pine bark extraction was performed using a $4 \mathrm{~L}$ extractor (bench scale) and a more realistic approach to obtain the process parameters to scale up to pilot and industrial scale extraction processes.

The objective of this work was to study bench scale extraction with different solvents and temperatures, and measure yields, composition and antioxidant properties. For all cases, anti-radical, reducing and chelating activities of the extracts were measured; phenols, tannins extracts, average molecular weight and phloroglucinolysis yields were determined; and the extract components were identified through comparison with standards.

\section{MATERIALS AND METHODS}

\section{Chemicals and reagents}

Standards of arabinose, ascorbic acid, (+)-catechin hydrate, galactose, glucose, mannose, taxifolin and xylose were used in the HPLC analysis were purchased to Sigma-Aldrich (St. Louis, MO, USA); as well, butylated hydroxytoluene (BHT), 2,2-diphenyl-1-picrylhydrazyl (DPPH), ferrous chloride, ferrozine, Folin-Ciocalteau reagent, gallic acid, iron III chloride, linoleic acid, phloroglucinol and 2,4,5-tri(2pyridyl)-s-triazine solution (TPTZ). Acetone, acetic acid, ethanol, hydrochloric acid and methanol were analysis grade; sulfuric acid and acetonitrile were HPLC grade and they were purchased to Merck (Darmstadt, Germany); as well as, sodium acetate, ferrous sulfate and sodium phosphate. Pygnogenol ${ }^{\mathbb{R}}$ (50 mg) was purchased to Prater Laboratory (Concepción, Chile). Also, ammonium sulphate (Sharlau, Barcelona, Spain), ammonium thiocyanate (Equilab, Santiago, Chile), methyl cellulose (BD Falcon, Franklin Lake, NJ, USA) and sodium carbonate (Arquimed, Santiago, Chile), were used in this study.

\section{Preparation and extraction}

P. radiata bark was obtained from the San Luis Farm, Yungay, Chile (May, 2010). Pine bark was ground with a mill (Condux, Hamilton, Canada) and classified with a sieve to a size $20 \pm 5 \mathrm{~mm}$ diameter (Williams 16-31, Concepción, Chile), dried to room temperature until obtaining equilibrium humidity $(\sim 12 \%)$, and then maintained at $23 \pm 1{ }^{\circ} \mathrm{C}$ in a room. Extraction was carried out in a $4 \mathrm{~L}$ reactor (P.Faudler, Schwetzingen, Germany) using $2 \mathrm{~L}$ of solvent and $100 \mathrm{~g}$ of pine bark (dry weight). After reaching operating temperature $\left(40{ }^{\circ} \mathrm{C}, 120^{\circ} \mathrm{C}\right.$ or $\left.160{ }^{\circ} \mathrm{C}\right)$, the time was initiated for $2 \mathrm{~h}$. Using a filter of 150 $\mu \mathrm{m}$, the wet bark was separated from the solution. The solution was then evaporated using a rotary evaporator (Ika Werke, Staufen, Switzerland) at $40{ }^{\circ} \mathrm{C}$, to eliminate the solvent used in the extraction. The aqueous extract was filtered using a Whatman paper filter No.1 $(11 \mathrm{~mm})$ to separate the watersoluble polyphenol fraction from the non-soluble particulate material at room temperature. Finally, the water-soluble polyphenol portion was freeze-dried (Labconco, Kansas City, MO, USA) at $-50{ }^{\circ} \mathrm{C}$ and 0.05 mbar, and kept in amber glass containers, sealed at $-20^{\circ} \mathrm{C}$.

\section{Extraction conditions}

A preliminary assessment of the effect of the temperature on the extraction yield and extract properties was studied. Some extractions were performed at higher temperatures $\left(120^{\circ} \mathrm{C}\right.$ and $\left.160{ }^{\circ} \mathrm{C}\right)$ than the boiling temperature of the solvent and so had pressures above atmospheric. 
After that, the effect of the organic solvent concentration on the extraction yield and extract properties was studied. Table 1 shows the extraction conditions to determine the solvent's influence on the pine bark extract yield at two temperatures $\left(\mathrm{T}_{1}=40^{\circ} \mathrm{C}\right.$ and $\left.\mathrm{T}_{2}=120^{\circ} \mathrm{C}\right)$.

Table 1: Batch extraction conditions to determine the solvent and temperature influence on the pine bark extract yield. Solvent/bark ratio: $20(\mathrm{~mL} / \mathrm{g}, \mathrm{w} / \mathrm{w})$.

Extraction time: 2 hours.

\begin{tabular}{cc}
\hline Solvent/water & $\% \mathbf{w} / \mathbf{w}$ \\
\hline Water & \\
Ethanol/Water & $25.0 \pm 0.2$ \\
Ethanol/Water & $50.0 \pm 0.2$ \\
Ethanol/Water & $75.0 \pm 0.2$ \\
Ethanol/Water & $98.7 \pm 0.2$ \\
Acetone/Water & $25.0 \pm 0.2$ \\
Acetone/Water & $50.0 \pm 0.2$ \\
Acetone/Water & $75.0 \pm 0.2$ \\
Acetone/Water & $98.7 \pm 0.2$ \\
\hline
\end{tabular}

\section{Extraction yield}

The results are expressed as \% grams of extract per gram of dry bark.

\section{Extract's moisture content and solubility}

To determine moisture, $50 \mathrm{~g}$ of extract were dried at $102^{\circ} \mathrm{C}$, according to Belscak-Cvitanovic et al. (2010) For solubility analysis, the extract was dissolved in $10 \mathrm{~mL}$ of distilled water at $30{ }^{\circ} \mathrm{C}$, stirring occasionally during $30 \mathrm{~min}$; the liquid was centrifuged (Heraeus Biofuge Primo, Frankfurt, Germany) at $5348 \mathrm{~g}$ for $10 \mathrm{~min}$, the supernatant was poured, and the solution was left at $105^{\circ} \mathrm{C}$ until constant weight.

\section{Total phenol content on the extracts}

The Folin-Ciocalteau method was performed as reported by Singleton and Rossi (1965) with modifications by Jerez et al. (2006). A pine extract sample of $0.5 \mathrm{~mL}(0.1 \mathrm{~g} / \mathrm{L})$ was mixed with $2.5 \mathrm{~mL}$ of Folin-Ciocalteau reagent $(2 \mathrm{~N})$ diluted at $10 \%(\mathrm{v} / \mathrm{v})$ and $2.0 \mathrm{~mL}$ of $75 \mathrm{~g} / \mathrm{L}$ of sodium carbonate. The solution was incubated for $15 \mathrm{~min}$ at $45^{\circ} \mathrm{C}$ and its absorbance was measured in a glass cuvette (path length $10 \mathrm{~mm}$ ) at $765 \mathrm{~nm}$ with a spectrophotometer (Shanghai Techcomp Instrument Ltd., Shanghai, China). A blank solution was prepared following the previous methodology, but replacing the extract with $2.5 \mathrm{~mL}$ of Milli- $\mathrm{Q}^{\mathrm{TM}}$ water. A calibration curve was performed using $0-60 \mathrm{mg} / \mathrm{L}$ of gallic acid aqueous solution as standard. Total phenol concentration of the extracts was expressed as the equivalent of $\mathrm{mg}$ of gallic acid/g of dry extract.

\section{Pine bark extracts tannin's concentration}

A methyl cellulose precipitation assay developed by Sarneckis et al. (2006) for grape extract and adapted by Maldonado (2008) for pine bark extract was used. Firstly, $0.5 \mathrm{~mL}$ of an aqueous solution of extract $(1.0 \mathrm{mg} / \mathrm{mL})$ was mixed with $1.5 \mathrm{~mL}$ of a $0.04 \%(\mathrm{w} / \mathrm{w})$ aqueous solution of methyl cellulose $(0.5$ $\mathrm{mL}, 1 \mathrm{~g} / \mathrm{L})$. Subsequently, $1.5 \mathrm{~mL}$ of a saturated solution of ammonium sulphate $(55 \mathrm{~g} / \mathrm{mL})$, and $1.5 \mathrm{~mL}$ of Milli- $\mathrm{Q}^{\mathrm{TM}}$ water were added and the sample was kept for $15 \mathrm{~min}$ at room temperature. The mixture 
was centrifuged at $2218 \mathrm{~g}$ for $5 \mathrm{~min}$ and the absorbance of the supernatant was measured at $280 \mathrm{~nm}$. The blank solution followed the same methodology, but replacing the methyl cellulose solution with 1.5 $\mathrm{mL}$ of Milli- $\mathrm{Q}^{\mathrm{TM}}$ water. Results were quantified by a calibration curve of $(+)$-catechin and expressed as equivalents of milligrams of $(+)$-catechin per gram of extract.

\section{DPPH assay}

The antiradical activity of the extracts was expressed as the percentage of antiradical activity (\%AA), measured by the sequestration of the radical 2,2-diphenyl-1-picrylhydrazyl (DPPH) as described by Ku and Mun (2008) and by Yassa et al. (2008). For the sample, $1 \mathrm{~mL}$ methanolic extract solution $(12 \mathrm{mg} / \mathrm{L})$ was mixed with $2 \mathrm{~mL}$ of methanolic solution of DPPH $(0.1 \mathrm{mmol} / \mathrm{L})$. For the blank, $1 \mathrm{~mL}$ of methanol was mixed with $2 \mathrm{~mL}$ of $0.1 \mathrm{mmol} / \mathrm{L}$ methanolic solution of DPPH, whereas for the control, $1 \mathrm{~mL}$ of methanolic extract solution $(12 \mathrm{mg} / \mathrm{L}$ ) was mixed with $2 \mathrm{~mL}$ of methanol. After $30 \mathrm{~min}$ in the dark, the absorbance was measured at $518 \mathrm{~nm}$ with the spectrophotometer. The antiradical activity was determined as $\% \mathrm{AA}=\left(1-\left(\left(\mathrm{Abs}_{\mathrm{m}}-\mathrm{Abs}_{\mathrm{c}}\right) / \mathrm{Abs}_{\mathrm{b}}\right)\right) * 100$, where \%AA stands for antiradical activity shown by the sample, while Absm, Absc and Absb correspond to sample, control and blank absorbances, respectively.

\section{Ferric reducing/ antioxidant power (FRAP) assay}

The extract's reducing activity was measured using the FRAP assay as described by Tian et al. (2009). The solution, 2,4,5-tri(2-pyridyl)-s-triazine (TPTZ) of $10 \mathrm{mmol} / \mathrm{L}$, was prepared in $40 \mathrm{mmol} / \mathrm{L}$ of hydrochloric acid. The FRAP solution was prepared mixing 10 volumes of sodium acetate buffer $(\mathrm{pH} 3.6,0.3 \mathrm{~mol} / \mathrm{L}), 1$ volume of TPTZ solution and 1 volume of iron(III) chloride $20 \mathrm{mmol} / \mathrm{L}$ solution. Analyses were performed mixing $3.6 \mathrm{~mL}$ of FRAP solution preheated at $37^{\circ} \mathrm{C}, 360 \mu \mathrm{L}$ of Milli- $\mathrm{Q}^{\mathrm{TM}}$ water and $120 \mu \mathrm{L}$ of $100 \mathrm{mg} / \mathrm{L}$ methanolic solution of bark extract. Then, the mixture was incubated at $37^{\circ} \mathrm{C}$ for $30 \mathrm{~min}$ in a temperature-controlled bath (Heidolph Instruments, Schwabach, Germany). The auto-zero of the spectrophotometer was made with acetate buffer; sample absorbance was measured at a wavelength of $595 \mathrm{~nm}$. A reagent blank was prepared, using the same procedure as for the samples, but replacing the extract with $120 \mu \mathrm{L}$ of methanol. Results were expressed in units of equivalent $\mathrm{g} \mathrm{Fe}^{+2} / \mathrm{g}$ extract by means of a calibration curve prepared with a methanolic solution of ferrous sulfate with a concentration range of 0.2 to $2.5 \mathrm{mmol} / \mathrm{L}$.

\section{Iron chelating activity (ICA) assay}

The chelating activity of obtained polyphenolic extracts was determined by ICA method (iron (II) chelating activity assay) according to Maqsood and Benjakul (2010). Firstly, $4.4 \mathrm{~mL}$ of extract methanolic solution $(2 \mathrm{~g} / \mathrm{L}), 100 \mu \mathrm{L}$ of $\mathrm{FeCl}_{2}(1 \mathrm{mmol} / \mathrm{L})$ and $200 \mu \mathrm{L}$ of ferrozine $(5 \mathrm{mmol} / \mathrm{L})$ in Milli-Q ${ }^{\mathrm{TM}}$ water were mixed. Samples were incubated for $20 \mathrm{~min}$ at room temperature and subsequently centrifuged (2218 $\mathrm{g} \mathrm{x} 5 \mathrm{~min}$ ). A reagent blank was made following the same procedure as for the samples, using $4.4 \mathrm{~mL}$ of distilled water instead of the extract solution. Furthermore, a blank sample was prepared following the previously described procedure, replacing the $\mathrm{FeCl}_{2}$ solution with distilled water. Sample absorbance was determined at a wavelength of $562 \mathrm{~nm}$ for all samples.

\section{Lipid peroxidation and ferric thiocyanate method (FTC)}

Lipid peroxidation and peroxide production's inhibition by the extracts was measured with the FTC method ( $\mathrm{Ku}$ and Mun 2008, Larrauri et al. 1996). The pine extracts $(0.8 \mathrm{~g} / \mathrm{L})$ were diluted with absolute ethanol. Linoleic acid (65\%) was diluted in ethanol up to $2.5 \% \mathrm{w} / \mathrm{w}$. The extract solution (7 $\mathrm{mL}$ ) was mixed with $14 \mathrm{~mL}$ of sodium phosphate $(0.3 \mathrm{~mol} / \mathrm{L}, \mathrm{pH} 7.0), 7 \mathrm{~mL}$ of deionized water and 7 $\mathrm{mL}$ of $2.5 \%$ linoleic acid. Control solution was prepared by mixing $14 \mathrm{~mL}$ of sodium phosphate, $7 \mathrm{~mL}$ of deionized water, $7 \mathrm{~mL}$ of $2.5 \%$ linoleic acid and $7 \mathrm{~mL}$ of absolute ethanol. The lipid peroxidation was placed in a tube with a screw cap, and placed in an oven at $40^{\circ} \mathrm{C}$ in the dark. Then, $100 \mu \mathrm{L}$ of the lipid/sample solution was mixed with $75 \%$ ethanol $(9.7 \mathrm{~mL})$ and $30 \%$ ammonium thiocyanate $(50 \mu \mathrm{L})$. Precisely $3 \mathrm{~min}$ after addition of $0.1 \mathrm{ml}$ of $0.02 \mathrm{~mol} / \mathrm{L}$ ferrous chloride in $3.5 \%$ hydrochloric acid to the reaction mixture, the absorbance was measured against a reagent blank at $500 \mathrm{~nm}$, each $24 \mathrm{~h}$, until the control reached maximum. Results were expressed as \% inhibition of the primary peroxidation (\%IPP). 


\section{Sugar analysis by HPLC}

The sugar content of the extract produced with acetone $75 \%(\mathrm{w} / \mathrm{w})$ at $40^{\circ} \mathrm{C}$ and at $160^{\circ} \mathrm{C}$ was measured by injection of the extracts using a HPLC, following the procedure by Mendonça et al. (2008). A sample (300 mg) was weighed in a test tube and $3 \mathrm{~mL}$ of $72 \%(\mathrm{w} / \mathrm{w})$ sulfuric acid was added. The hydrolysis was carried out in a water bath at $30^{\circ} \mathrm{C}$ for $1 \mathrm{~h}$ with stirring every $10 \mathrm{~min}$. Later, the acid was diluted to $3 \%(\mathrm{w} / \mathrm{w})$ with $79 \mathrm{~mL}$ of distilled water and the mixture was transferred to a $250 \mathrm{~mL}$ Erlenmeyer flask and autoclaved for $1 \mathrm{~h}$ at $121{ }^{\circ} \mathrm{C}$. The residual material was cooled and filtered through a number 3 sintered-glass filter. Solids were dried to constant weight at $105^{\circ} \mathrm{C}$ and determined as insoluble lignin. Soluble lignin was determined by measuring the absorbance of the solution at $205 \mathrm{~nm}$. The concentration of monomeric sugars in the soluble fraction was determined by HPLC with refractive index detector (Merck Hitachi, Tokyo, Japan) and a column HPX87H (Biorad, Hercules, CA, USA) at $45^{\circ} \mathrm{C}$, eluted at $0.6 \mathrm{~mL} / \mathrm{min}$ with $5 \mathrm{mM}$ sulfuric acid and using a refractive index detector. The results were expressed as $g$ of glucose/L, $g$ of xylose + mannose + galactose/L and $g$ of arabinose/L.

\section{Proanthocyanidins analysis by HPLC}

Proanthocyanidins of extracts were depolymerized by acid hydrolysis in presence of phloroglucinol (Kennedy and Taylor 2003, Cortés et al. 2010). RP-HPLC (Younglin, Shanghai, China) equipped with a RP-18E column, $3.0 \times 150 \mu \mathrm{m}, 5 \mu \mathrm{m}$ (Merck Chromolith, Darmstadt, Germany) and a UV-VIS detector (Younglin, Shanghai, China) were used for gradient liquid chromatography. The extract was mixed in an ultrasound bath with $10 \mathrm{mg} / \mathrm{L}$ of a solution, containing $0.1 \mathrm{~mol} / \mathrm{L}$ hydrochloric acid in methanol, 50 $\mathrm{g} / \mathrm{L}$ phloroglucinol and $10 \mathrm{~g} / \mathrm{L}$ ascorbic acid. Then, the mixture was filtered through $0.45 \mu \mathrm{m}$ (Membrane Solutions, Lane Plano, TX, USA), and $20 \mu \mathrm{L}$ were injected into RP-HPLC. The method used a binary gradient with A: water containing $1 \%(\mathrm{v} / \mathrm{v})$ aqueous acetic acid and $\mathrm{B}$ : acetonitrile containing $1 \%(\mathrm{v} / \mathrm{v})$ acetic acid. Eluting peaks were monitored at $280 \mathrm{~nm}$, and the elution conditions were as follows: column temperature $30{ }^{\circ} \mathrm{C} ; 3.0 \mathrm{~mL} / \mathrm{min} ; 3 \% \mathrm{~B}$ for $4 \mathrm{~min}$, a linear gradient from $3 \%$ to $18 \%$ B in $10 \mathrm{~min}$, and $80 \% \mathrm{~B}$ for $2 \mathrm{~min}$. The parameters were calculated using the $100 \mathrm{mg} / \mathrm{L}$ standards of $(+)$-catechin and taxifolin. The average molecular weight (aMW) and the phloroglucinolysis yield (\%PY) were calculated (Kennedy and Jones 2001).

\section{Statistical analysis}

All the extract's chemical antioxidant analysis and the HPLC characterization data were the results of the means from three independent replicates $(n=3)$. All data are reported as mean value \pm SD. The calculation of mean values and standard deviation was performed by Microsoft Excel ${ }^{\circledR} 2003$.

\section{RESULTS AND DISCUSSION}

\section{Preliminary assessment of the temperature effect on the extraction yield}

Highest yields were achieved with water, reaching $11.99 \%$ at $120^{\circ} \mathrm{C}(\mathrm{p}<0.05)$. The extracts obtained at $160^{\circ} \mathrm{C}$ were dense, viscous, caramelized and presented a non-homogeneous composition, which would cause pipe plugging at commercial plant scale. At $160^{\circ} \mathrm{C}$, eventually polysaccharide hydrolysis and subsequent dehydration to furans occurred but this was not measured.

The sugar content of two extracts obtained with an acetone/water mixture at $40{ }^{\circ} \mathrm{C}$ and at $160{ }^{\circ} \mathrm{C}$, respectively, were analyzed and the results are presented in Table 2 . The extract obtained at $160^{\circ} \mathrm{C}$ had more sugar concentrations than obtained at $40{ }^{\circ} \mathrm{C}$, explaining its larger density and viscosity. Therefore, and due to this extract's physical characteristics, the maximum operation temperature was limited to $120^{\circ} \mathrm{C}$. 
Table 2. Sugar analysis of pine bark extracts obtained with an acetone/water mixture as solvent.

\begin{tabular}{clc}
\hline $\begin{array}{c}\text { Extraction } \\
\text { temperature }\left({ }^{\circ} \mathbf{C}\right)\end{array}$ & \multicolumn{1}{c}{ Composition of extract } & Concentration $(\mathbf{g} / \mathbf{L})$ \\
\hline & Glucose & $0.710 \pm 0.007$ \\
40 & Xylose+Mannose+Galactose & $0.095 \pm 0.001$ \\
& Arabinose & $0.009 \pm 0.001$ \\
\hline 160 & Glucose & $0.550 \pm 0.004$ \\
& Xylose+mannose+galactose & $1.400 \pm 0.009$ \\
& Arabinose & $1.500 \pm 0.013$ \\
& &
\end{tabular}

Extraction conditions: acetone $/$ water $7 / 3(\mathrm{v} / \mathrm{v})$, solvent/ bark ratio $=20 \mathrm{~mL} / \mathrm{g}$, extraction period $=2 \mathrm{~h}$.

\section{Extraction Yield}

Figure 1 shows the bark's extraction yields for the different organic solvent at 40 and $120^{\circ} \mathrm{C}$. No caramelization was observed in these products. The yields at $40{ }^{\circ} \mathrm{C}$ were smaller than one half of the yields at $120^{\circ} \mathrm{C}$. The largest yields were obtained using water, which shows that polar solvents produce the highest extraction. To choose the best extract, however, information related to their physicochemical and antioxidant properties is needed.

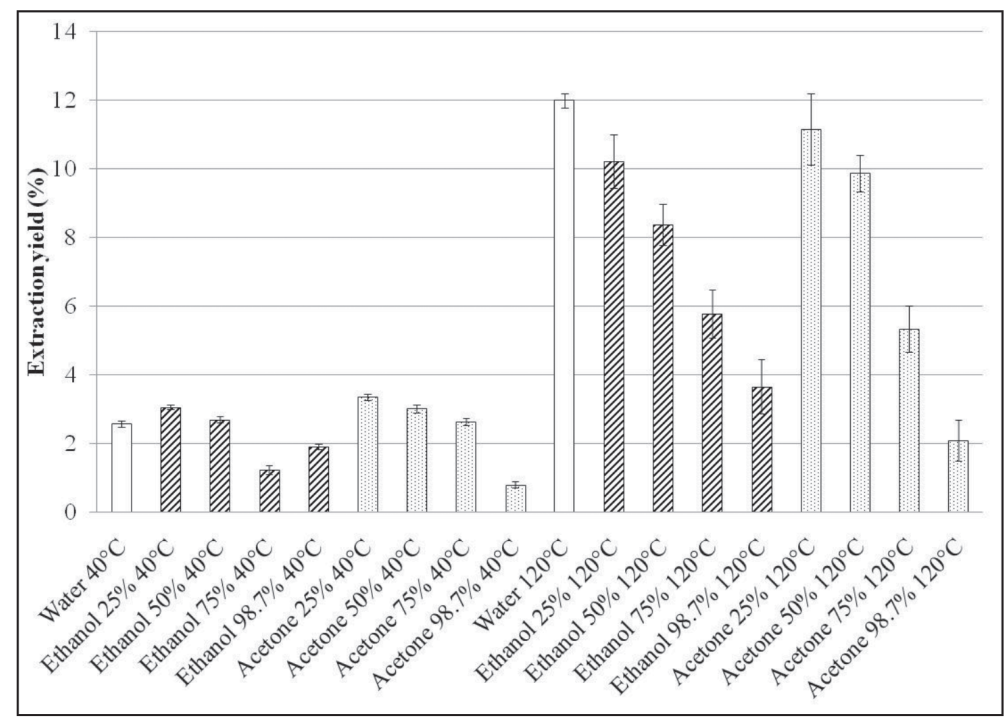

Figure 1. Effect of temperature and organic solvent concentration (Acetone: $:$ Ethanol: $/ 2$ and Water:D) on the pine bark extraction yield. Extraction period $=2 \mathrm{~h}$; solvent/ bark ratio $(\mathrm{v} / \mathrm{w})=20 \mathrm{~mL} / \mathrm{g}$. 


\section{Extract's moisture content and solubility}

The moisture and solubility of the extracts were determined to evaluate the influence of the extraction solvent. The extract obtained with water had the highest moisture content $(12.1 \%)$, probably due to absorption of water molecules from the environment because of its higher hidrophilicity. In contrast, the six extracts obtained with the ethanol/water $(25,50$ and $75 \% \mathrm{w} / \mathrm{w})$ and acetone/water $(25,50$ and $75 \%$ $\mathrm{w} / \mathrm{w}$ ) mixtures did not differ significantly, showing average moistures of $7.6 \pm 1.2 \%$. Extract solubility did not show significant differences between the extracts with a mean value of $17.5 \pm 0.2 \mathrm{~g} / \mathrm{L}$.

\section{Total phenols and tannins concentration}

Increased temperature causes a decrease in total phenols and tannin concentrations (Figure 2) except for the extractions with high organic solvent content $(75 \%$ and $98.7 \%)$, i.e., it was possible that extract denaturation occurred at $120^{\circ} \mathrm{C}$. The extraction at $120^{\circ} \mathrm{C}$ with water had a $\mathrm{C}_{\text {PHENOLS }}: 0.172 \mathrm{~g}$ of gallic acid/g extract; this concentration was smallest than all other extracts. The highest total phenols concentration was obtained with acetone $98.7 \%$ at $40^{\circ} \mathrm{C}$ and $120^{\circ} \mathrm{C}$. The same behavior was observed for the tannins concentration. Pinelo et al. (2005), also obtained a larger total phenols concentration when ethanol instead of water was used as solvent.

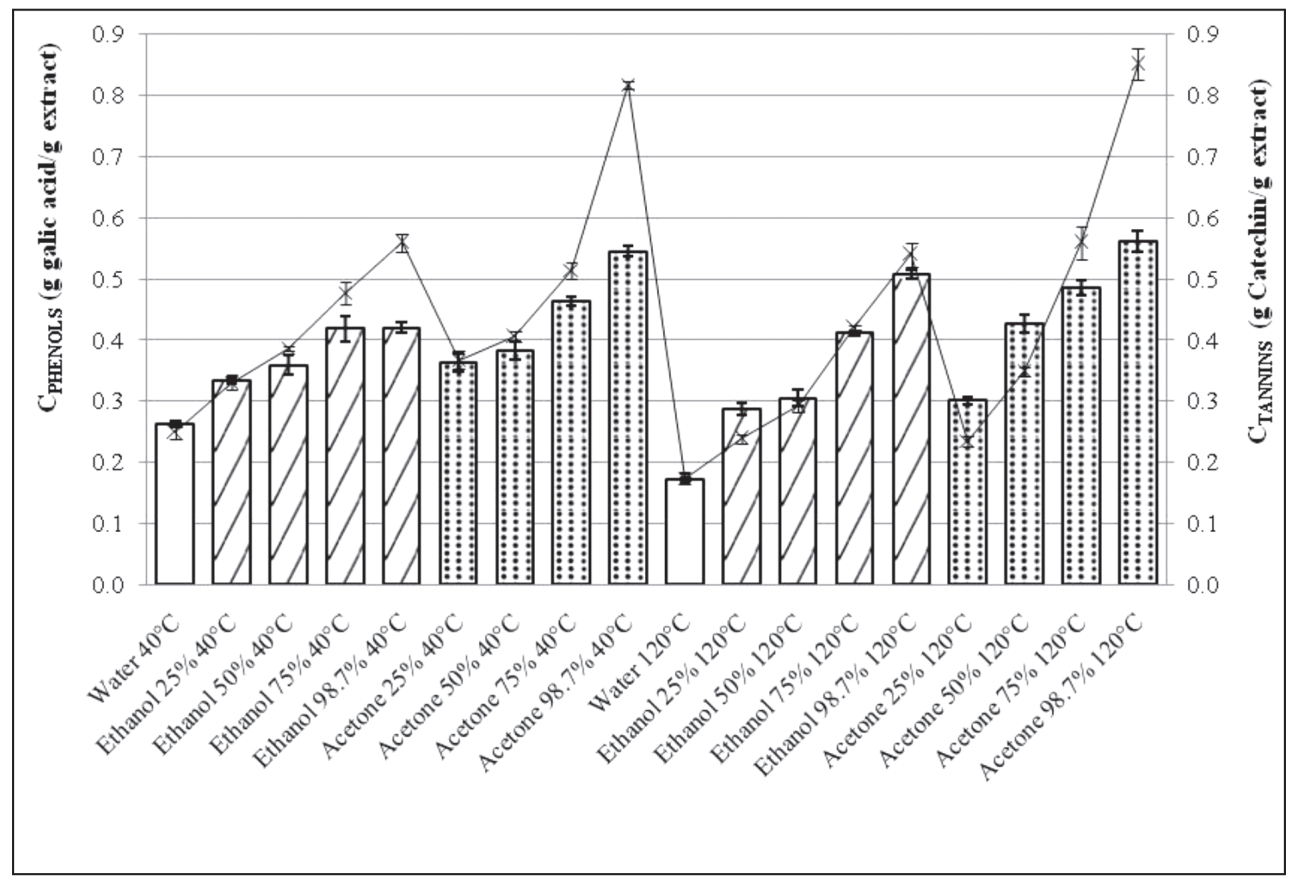

Figure 2. Effect of temperature and organic solvent concentration on the total phenol content (Acetone: extracts.

\section{Antioxidant properties}

It is difficult to evaluate the antioxidant activity of a compound based on a single method due to the complexity of mechanisms involved in oxidation reactions (Viuda-Martos et al. 2010). Therefore, in this work, many methods such as those that measure anti-radical activity (DPPH), reducing (FRAP) and iron chelating (ICA) activities, and peroxide production's inhibition in linoleic acid (FTC) were evaluated to characterize pine extract antioxidant capacity. 


\section{Anti-radical, reducing and iron chelating activities}

Many researchers report anti-radical activity for pine extracts, although reducing and chelating activity is scarcely reported. It is important to measure the reducing activity or ferric reducing/antioxidant power (FRAP) because phenols antioxidant power are considered to be related to their redox properties, which act as reducing agents (Kähkönen 1999). Also, the ability to form molecular complexes with heavy metals is very important for fat oxidation since these are capable of catalyzing the oxidation process (Lantto et al. 2009). Thus, in order to determine antioxidant properties, antiradical, reducing and chelating activities all should be determined.

Figure 3 shows the antiradical, reducing and chelating activities of the 18 studied extracts. The antiradical activity of the extracts increased when the organic solvent percentage was raised, reaching the highest value of $41 \% \mathrm{AA}$ with acetone $\left(98.7 \%\right.$ at $40^{\circ} \mathrm{C}$ and $\left.120^{\circ} \mathrm{C}\right)$. Ku et al. (2007) reported values of $92.5 \%$ of anti-radical activity, working with $P$. radiata extracts $(25 \mu \mathrm{g} / \mathrm{mL})$, equivalent to $44.4 \%$ of AA in the extract concentrations used in our work. For $P$. radiata bark extracts $(0.15 \mathrm{~g} / \mathrm{L})$ produced with acetone, Maldonado (2008) reported $86 \% \mathrm{AA}$ at $35^{\circ} \mathrm{C}$, equivalent to $6.88 \%$ of antiradical activity using the extract concentration reported in our work. The extracts presented here are similar to those of Ku et al. (2007), who also found good antiradical activity.

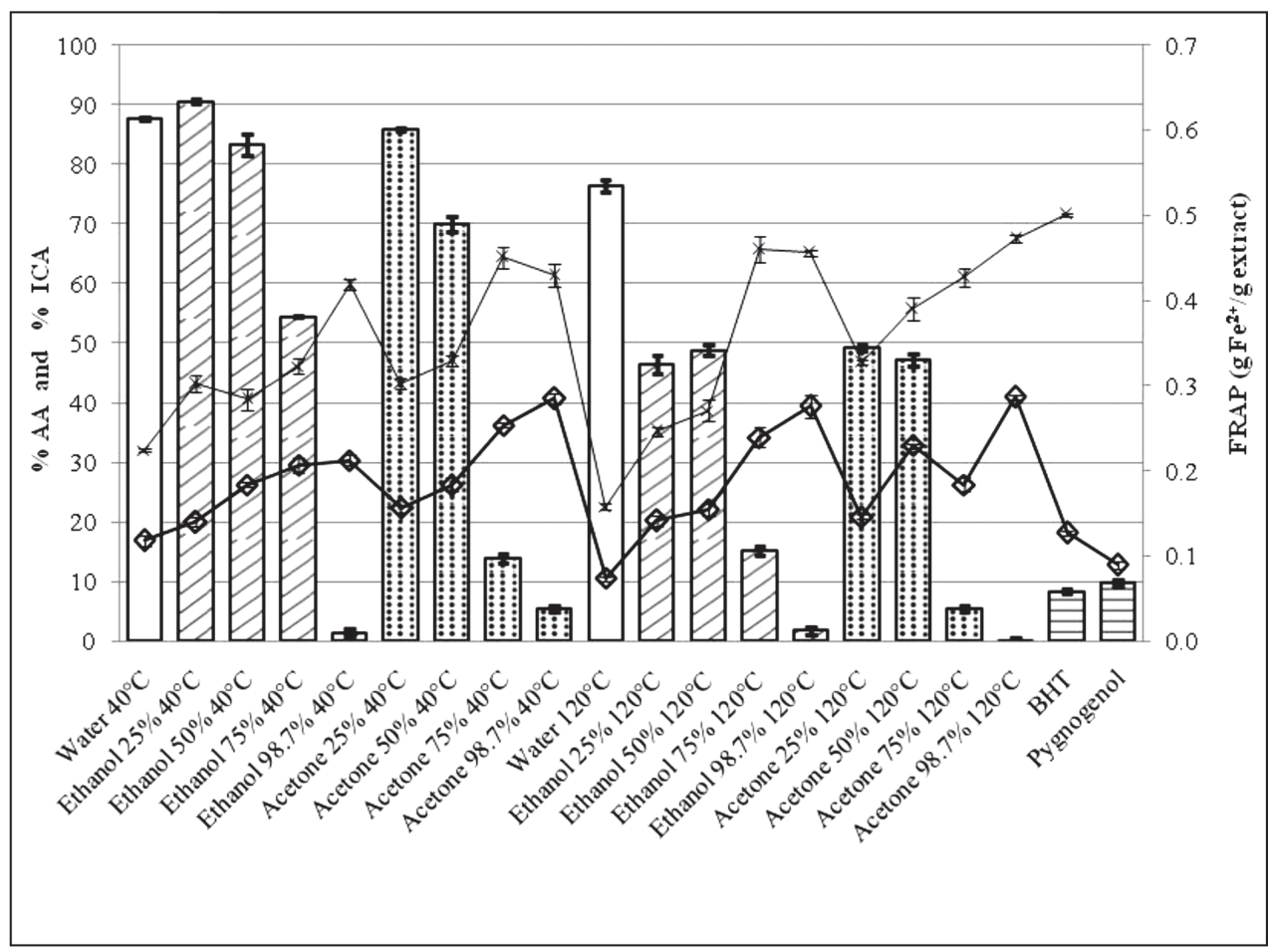

Figure 3. Effect of temperature and organic solvent concentration on the iron chelating

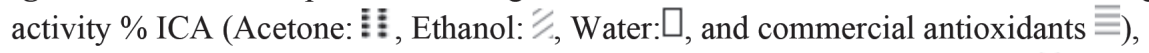
antiradical activity \%AA $(\diamond)$ and ferric reducing/antioxidant power or FRAP $(*)$ of pine bark extracts.

Extraction period: $2 \mathrm{~h}$; solvent/ bark ratio $(\mathrm{v} / \mathrm{w})=20 \mathrm{~mL} / \mathrm{g}$. 
A tendency similar to the antiradical activity was observed for the experimental reducing activity data (FRAP), where the maximum value was $0.47 \mathrm{~g} \mathrm{Fe}^{2+} / \mathrm{g}$ extract for the extracts obtained with $98.7 \%$ of acetone at $120^{\circ} \mathrm{C}$. The behavior of both antiradical and reducing activities reveals that the compounds responsible for the free radical scavenging and reduction are more easily extracted with solvents less polar than the water. Several extracts decreased their antiradical and reducing activity when the extraction temperature was raised to $120{ }^{\circ} \mathrm{C}$. Comparable results were reported using Galla chinensis extracts (Tian et al. 2009).

Similar to the anti-radical and reducing activity, ICA values decreased when the extraction temperature increased; nevertheless, the effect of the type of organic solvent and the mass proportions on ICA were different. Indeed, ICA decreased when the proportion of organic solvent increased, showing no chelating activity for the extract obtained with $98.7 \%$ acetone at $120^{\circ} \mathrm{C}$. This phenomenon has been observed when non-polar solvents are used to extract pine bark. Indeed, the effect of these compounds on metals is inhibited due to the activity of the metoxi groups without affecting their antiradical and reducing activity (Maqsood and Benjakul 2010 and Jerez et al. 2009). Jerez et al. (2009) have reported the presence of ferulic acid rich in metoxi groups when $P$. radiata bark was extracted with $99.5 \%$ ethanol at $37.5^{\circ} \mathrm{C}$. This result could explain the low chelating activity and high antiradical/reducing activities when high organic solvents are used.

Low ICA values for the extracts obtained with a high ratio of organic solvent were similar to the ICA values for the commercial antioxidants: BHT and Pygnogenol. Both commercial antioxidants showed ICA values equal or lower than $10 \%$. The extracts obtained with a solvent concentration $<75 \%$ showed higher values of \%AA, FRAP and ICA than the commercial antioxidants.

\section{Measurement of the inhibition of peroxide production in linoleic acid}

For the extracts with the best extraction yield and anti-radical, reducing and chelating activities, the inhibition of primary lipid peroxidation in linoleic acid (IPP) was measured. The best performance was for BHT (IPP of 97.42\%), followed by extract obtained with water (IPP of 92.6\%). One cause for this behavior could be the water affinity of extracts in the solution of linoleic acid/ water solution leading to a larger dissolution of the extracts, and therefore a better action and results. However, the extracts obtained with organic solvents also showed high IPP values; for example, extracted obtained with 50 and $75 \%$ of ethanol registered IPP of 87.9 and $81.7 \%$ respectively.

\section{Relation between extract's properties}

The anti-radical and reducing activities of the extracts presented a direct relationship $\left(\mathrm{R}^{2}=0.829\right)$. Similar behavior was reported (Jerez et al. 2007a) for plants and pine extracts $\left(\mathrm{R}^{2}=0.822\right)$. Thus, when an extract shows high antiradical activity, it also exhibits high reducing activity. Also a linear relationship between the experimental values of DPPH and total phenols $\left(\mathrm{R}^{2}=0.884\right)$ was found. Thus, phenols have influence of on the antiradical activity of the extracts and on the possible antioxidant activity since a larger number of phenolic groups implies a larger group of hydroxyl groups, which are potentially capable of trapping free radicals. In pine bark extracts, these groups are mainly provided by proanthocyanidins. The relationship between anti-radical activity and tannins concentration was also direct $\left(\mathrm{R}^{2}=0.726\right)$. Thus, it is believe that not only tannins but a combination of many types of phenols are responsible for antiradical activity.

\section{Extraction yield-antioxidant activity optimization}

When the organic solvent to pine bark ratio $(\mathrm{v} / \mathrm{w})$ was increased, extracts total phenols and tannins concentration increased. Also, anti-radical and reducing activity behavior was similar, while chelating activity and lipid oxidation decreased. When the temperature was raised from $40{ }^{\circ} \mathrm{C}$ to $120^{\circ} \mathrm{C}$, there was also a decrease in the measured extract properties and at the same time an increase in the extraction yields; although, the increase in the extraction yield was larger than the decrease of the former properties. Since both, the extract antioxidant properties and the extraction yield have to be considered when choosing the most attractive extract, the results were expressed as a product of both properties (Table 3). 
Table 3 shows that the most attractive extractions were done with water at $120{ }^{\circ} \mathrm{C} ; 25 \%$ and $50 \%$, ethanol at $120{ }^{\circ} \mathrm{C}$, and $25 \%, 50 \%$ and $75 \%$ acetone at $120{ }^{\circ} \mathrm{C}$. The main advantages of the extract obtained with water at $120^{\circ} \mathrm{C}$ are high yield, chelating activity and inhibition of primary lipid oxidation; nevertheless, this extract had the lowest antiradical and reducing activity, phenols and tannins concentration, i.e., their bioactive properties are low when compared to other extracts (Ku et al. 2008, Pinelo et al. 2005, Lantto et al. 2009).

When acetone was the extraction solvent, yields were similar to those obtained with ethanol but the extracts showed higher values of anti-radical and reducing activity, phenols and tannins concentration. Thus, these could be the best extracts, although acetone handling is considered riskier than ethanol usage (according to National Institute for Occupational Safety and Health and the American Conference of Governmental Industrial Hygienists). In addition, if extracts are to be used in food, ethanol is more recommended as extracting agent (Shi et al. 2005). In conclusion, the best extracts for flexible use and their properties are those obtained with $25 \%$ and $50 \%$ ethanol.

This study shows that the use of different extraction process conditions generates extracts with diverse chemical and physical characteristics. Wu et al. (2011), have determined that the chelating activity is an important characteristics of anticancer agents, and therefore those extracts with high ICA and low values of \%AA and FRAP are potential anticancer agents. On the other hand, those extracts obtained with a high organic proportion (high \%AA and FRAP, and low values of ICA) can be used as antioxidant agents in food and paint industries.

\section{Proanthocyanidins analysis by HPLC}

The 18 extracts were characterized using RP-HPLC after catalysis acid with phlorglucinol. Two

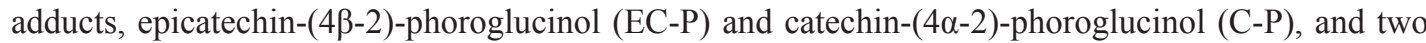
monomers, $(+)$-catechin $(\mathrm{C})$, taxifolin $(\mathrm{T})$, were detected and quantified. Retention times were in accordance with results previously published (Cortés et al. 2010).

Figure 4 shows retention times of $10 \mathrm{~g} / \mathrm{L}$ extract obtained at $40{ }^{\circ} \mathrm{C}$ with $75 \%$ acetone. The 18 extracts had the same compounds. After component identification, the phloroglucinolysis yield (\%PY) and the average molecular weight (aMW) were determined. Figure 5 shows that $\% \mathrm{PY}$ increases with the increase in organic solvent proportion. For both temperatures, acetone as solvent produced larger yields than ethanol or water. The increase in temperature was detrimental to the performance, which agrees with the antioxidant characterization of the extracts (Figure 3) and their phenol and tannins concentration.

The extraction temperature was the parameter that most influenced the aMW: when it was raised from 40 to $120^{\circ} \mathrm{C}$, the aMW decreased $44 \%$. The aMW ranged between 552 and $1251 \mathrm{~g} / \mathrm{mol}$, similar to those reported for pine bark extract using GPC (Weber et al. 2007).

Taxifolin identification led to the discovery that the phenolic compounds had the highest concentration, followed by $(+)$-catechin. This identification was not confirmed in previous reports (Cortés et al. 2010). 


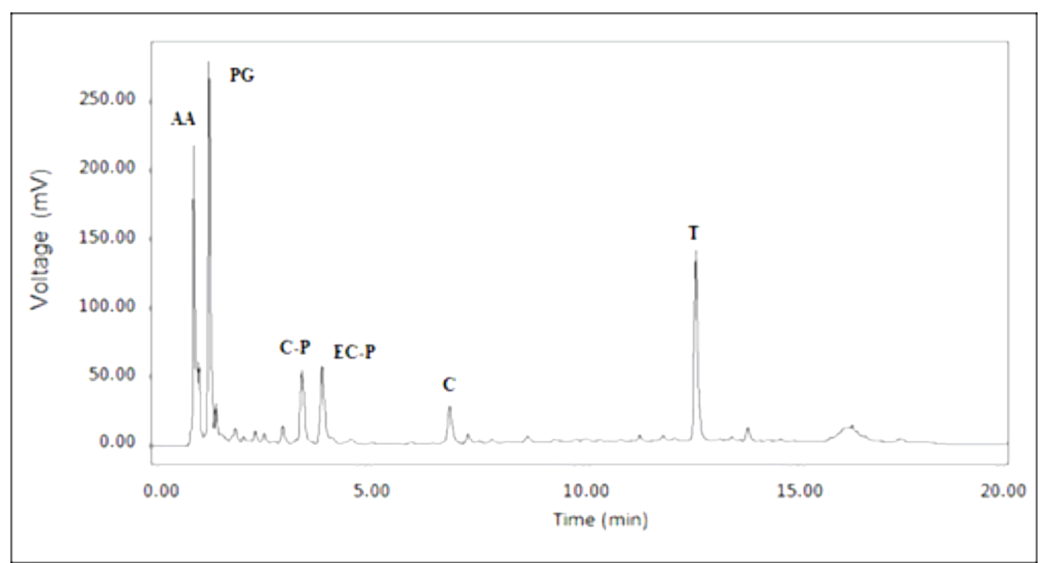

Figure 4. Chromatogram from batch extract obtained with $75 \%(w / w)$ acetone at $40^{\circ} \mathrm{C}$, solvent $/$ bark ratio $=20 \mathrm{~mL} / \mathrm{g}$; extraction period of $2 \mathrm{~h}$. AA: Ascorbic acid; PG:

Phloroglucinol; C-P: Catechin-Phloroglucinol adduct; EC-P:Epicatechin-Phloroglucinol adduct; $\mathrm{C}:(+)-$ Catechin and T: Taxifolin.

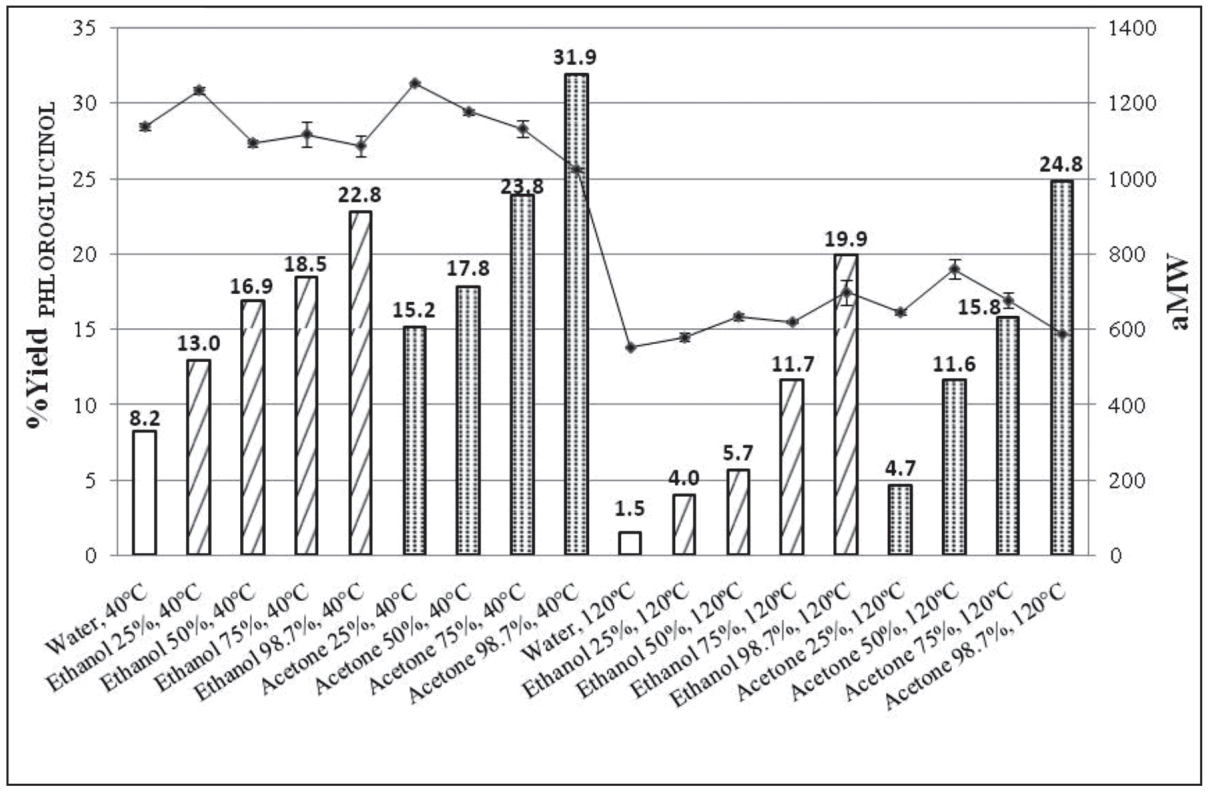

Figure 5. Temperature and organic solvent concentration effect on phloroglucinolysis

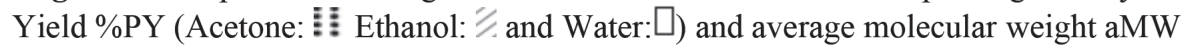

$(-)$ content in extracts from pine bark.

Extraction period $=2 \mathrm{~h}$; solvent/bark ratio $(\mathrm{v} / \mathrm{w}): 20 \mathrm{~mL} / \mathrm{g}$. 


\section{CONCLUSIONS}

Phenols bench extraction from pine bark was performed with different process conditions and the extracts were characterized in terms of an extraction optimization. At extraction temperature of $160^{\circ} \mathrm{C}$, caramelization and non-homogeneous physical characteristics were observed, making scaling up at 160 ${ }^{\circ} \mathrm{C}$ infeasible. When the temperature decreased from 120 to $40{ }^{\circ} \mathrm{C}$ or when the organic solvent ratio was increased, extraction yields decreased and larger phenols and tannins concentration and bioactivities were observed. The anti-radical activity of the extracts increased when the organic solvent percentage was raised. The behavior of both antiradical and reducing activities reveals that the compounds responsible for the free radical scavenging and reduction are more easily extracted with solvents less polar than the water. The best extraction conditions for high extractive yield and antioxidant properties was achieved with ethanol/water at $120{ }^{\circ} \mathrm{C}$. The chromatographic information indicated that the extract's main components were catechin and taxifolin.

\section{ACKNOWLEDGEMENTS}

The authors thank to the project Innova Bio Bio, Chile 08-PC S1-470 for the financial support.

\section{REFERENCES}

Belscak-Cvitanovic, A.; Bonkovic, M.; Komes, D.; Bauman, I.; Horzic, D.; Dujmic, F.; Matijasec, M. 2010. Physical Properties and Bioactive Constituents of Powdered Mixtures and Drinks Prepared with Cocoa and Various Sweeteners. J. of Agric. Food Chem 58 (12): 7187-7195.

Botterweck, A. M.; Verhagen, H.; Goldbohm, R. A.; Kleinjans, J.; Van Den Brandt, P. A. 2000. Intake of Butylated hydroxyanisole and Butylated hydroxytoluene and Stomach cancer risk: Results from analysis in the Netherlands Cohort Study. Food and Chem. Toxic 38(7): 599-605.

Cortés, S.; Pulgar, H.; Sanhueza, V.; Aspé, E.; Fernández, K. 2010. Identification of proanthocyanidins extracted from P. radiata bark. Cien. Inv. Agr. 37(2): 15-25.

Diouf, P. N.; Merlin, A.; Perrin, D. 2006. Antioxidant properties of wood extracts and colour stability of woods. Ann. For. Sci. 63: 525-534.

Dudonné, S.; Vitrac, X.; Coutiere, P.; Woillez, M.; Merillon, J. M. 2009. Comparative Study of Antioxidant Properties and Total Phenolic Content of 30 Plant Extracts of Industrial Interest Using DPPH, ABTS, FRAP, SOD, and ORAC Assays. J. Agric. Food Chem. 57(5): 1768-1774.

Fukumoto, L. R.; Mazza, G. 2000. Assessing Antioxidant and Prooxidant Activities of Phenolic Compounds. J. Agric. Food. Chem. 48(8): 3597-3604.

Heimler, D.; Isolani, L.; Vignolini, P.; Tombelli, S.; Romani, A. 2007. Polyphenol content and antioxidative activity in some species of freshly consumed salads. J. Agric. Food Chem. 55(5): 1724-1729.

Jerez, M.; Pinelo, M.; Sineiro, J.; Núñez, M. 2006. Influence of extraction conditions on phenolic yields from pine bark: assesment of procyanidins polymerization degree by thiolysis. Food Chem. 94(3): 406-414. 
Jerez, M.; Selga, A.; Sineiro, J.; Torres, J.; Núñez, M. 2007a. A comparison between bark extracts from Pinus Pinaster and Pinus radiata: Antioxidant activity and procyanidin composition. Food Chem 100(2): 439-444.

Jerez, M.; Touriño, S.; Sineiro, J.; Tores, J.; Núñez, M. 2007b. Procyanidins from pine bark: Relationships between structure, composition and antiradical activity. Food Chem. 104(2): 518-527.

Jerez, M.; Sineiro, J.; Núñez, M. J. 2009. Fractionation of pine bark extracts: selecting procyanidins. Eur. Food Res. Technol. 229(4): 651-659.

Kähkönen, M. P.; Hopia, A. I.; Vuorela, H. J.; Rauha, J. P.; Pihlaja, K.; Kujala, T. S.; Heinonen, M. 1999. Antioxidant Activity of Plant Extracts Containing Phenolic Compounds. J. Agric. Food. Chem. 47 (10): 3954-3962.

Kennedy, J. A.; Jones, G. P. 2001. Analysis of Proanthocyanidin Cleavage Products Following Acid-Catalysis in the Presence of Excess Phloroglucinol. J. Agric. Food. Chem. 49(4): 1740-1746.

Kennedy, J. A.; Taylor, A.W. 2003. Analysis of proanthocyanidins by high-performance gel permeation chromatography. $J$. of Chrom. 995(1-2): 99-107.

Ku, C. S.; Jang. P. J.; Mun, S. P. 2007. Explotation of polyphenol-rich pine barks for potent antioxidant activity. J. Wood Sci. 53(6): 524-528.

Ku, C. S.; Mun, S. P. 2008. Antioxidant properties of monomeric, oligomeric, and polymeric fractions in hot water extract from Pinus radiata bark. Wood Sci. Technol. 42(1): 47-60.

Lantto, T. A.; Dorman, H. J. D.; Shikov, A. N.; Pozharitskaya, O. N.; Makarov, V. G.; Tikhonov, V. P.; Hiltunen, R.; Raasmaja, A. 2009. Chemical composition, antioxidative activity and cell viability effects of a Siberian pine (Pinus sibirica Du Tour) extract. Food Chem. 112(4): 936-943.

Larrauri, J. A.; Goñi, I.; Martin-Carrón, N.; Rupérez, P.; Saura-Calixto, F. 1996. Measumerent of Health-Promoting Properties in Fruit Dietary Fibres: Antioxidant Capacity, Fermentability and Glucose Retardation Index. J. Sci. Food Agric. 71(4): 515-519.

Maldonado, J. 2008. Natural antioxidant production from Pinus Radiata D. Don (Obtención de un antioxidante natural a partir de corteza de Pinus Radiata D. Don) Undergraduate Thesis in Chemical Engineering, University of Concepción, Concepción, Chile. 25-54

Maqsood, S.; Benjakul, S. 2010. Comparative studies of four different phenolic compounds on in vitro antioxidative activity and the preventive effect on lipid oxidation of fish oil emulsion and fish mince. Food Chem. 119(1): 123-132.

Mendoça, R. T.; Jara, J. F.; González, V.; Elissetche, J. P.; Freer, J. 2008. Evaluation of the white-rot fungi Ganoderma australe and Ceriporiopsis subvermispora in biotechnological applications. J. Ind. Microbiol. Biotechnol 35(11): 1323-1330.

Pinelo, M.; Rubilar, M.; Jeréz, M.; Sineiro, J.; Núñez, M. J. 2005. Effect of Solvent, Temperature, and Solvent-to Solid Ratio on the Total Phenolic Content and Antiradical Activity of Extracts from Different Components of Grape Pomace. J. Agric. Food Chem. 53(6): 2111-2117. 
Rahim, A. A.; Rocca, E.; Steinmetz, J.; Kassim, M.J.; Ibrahim, M. S.; Osman, H. 2008. Antioxidant activities of mangrove Rhizophora apiculata bark extracts. Food Chem. 107(1): 200-207.

Romani, A.; Vignolini, P.; Isolani, L.; Ieri, F.; Heimler, D. 2006. HPLC-DAD/MS Characterization of flavonoides ans hydroxycinnamic derivates in Turnip Tops (Brassica rapa L. Subsp. Sylvestris L.). J. Agric. Food Chem. 54(4): 1342-1346.

Rupasinghe, H. P. V.; Erkan, N.; Yasmin, A. 2010. Antioxidant protection of Eicosapentaenoic acid and fish oil oxidation by polyphenolic-enriched apple skin extract. J. Agric. Food. Chem. 58(2): 1233-1239.

Sarneckis, C. J.; Dambergs, R. G., Jones, P.; Mercurio, M.; Herderich, M. J.; Smith, P. A. 2006. Quantification of condensed tannins by precipitation with methyl cellulose: Development and validation of an optimised tool for grape and wine analysis. Aust. J. Grape Wine Res 12(1): 39-49.

Shi, J.; Nawaz, H.; Pohorly, J.; Mittal, G.; Kakuda, Y.; JIANG, Y. 2005. Extraction of Polyphenolics from Plant Material for Functional Foods-Engineering and Technology. Food Rev. Int. 21(1): 139-166.

Singleton, V. L.; Rossi, J. A. 1965. Colorimetry of total phenolics with phosphomolybdic phosphotungstic acid reagents. Amer. J. Enol. Viticult. 16(3): 144-158.

Tian, F.; Li, B.; Ji, B.; Yang, J.; Zhang, G.; Chen, Y.; Luo, Y. 2009. Antioxidant and antimicrobial activities of consecutive extracts from Galla chinensis: The polarity affects the bioactivities. Food Chem. 113(1): 173-179.

Treybal, R.E. 2001. Mass transfer Operations. Mc Graw Hill: Ciudad de México, México. 625-675.

Viuda-Martos, M.; El-Gendy, A. E.; Sendra, E.; Fernández-López, J.; Abd El Razik, K. A.; Omer, E. A.; Pérez-Álvarez, J. A. 2010. Chemical Composition and Antioxidant and Anti-Listeria Activities of Essential Oils Obtained from Some Egyptian Plants. J. Agric. Food Chem. 58(16): 9063 9070.

Weber, H. A.; Hodges, A. E.; Guthrie, J. R.; O’brien, B. M.; Robaugh, D.; Clark, A. P.; Harris, R. K.; Algaier, J. W. Smith, C. S. 2007. Comparison of Proanthocyanidins in Commercial Antioxidants: Grape Seed and Pine Bark Extracts. J. Agric. Food Chem. 55(1): 148-156.

Wu, C.; Miller, P. A.; Miller, M. J. 2011. Syntheses and studies of amamistatin B analogs reveals that anticancer activity is relatively independent of stereochemistry, ester or amide linkage and select replacement of one of the metal chelating groups. Bioorg. Med. Chem. Lett. 21(9): 2611-2615.

Yassa, N.; Beni, H. R.; Hadjiakhondi, A. 2008. Free Radical Scavenging and Lipid Peroxidation Activity of the Shahani Black Grape. Pak. J. Biol. Sci. 11(21): 2513-2516. 